\title{
PERSEPSI MASYARAKAT TERHADAP PELAYANAN KESEHATAN PADA PUSTU RANTE MALOLIN KELURAHAN PETA KECAMATAN SENDANA KOTA PALOPO
}

\author{
ABDUL HALIK, MUH. HALIM, SAMSUL BACHRI
}

\begin{abstract}
ABSTRAK
Pelayanan kesehatan merupakan satu hal yang sangat penting untuk diperhatikan. Siapa pun berhak untuk mendapatkan pelayanan kesehatan, baik di kota maupun di desaa. Di daerah perkotaan pemerintah ataupun pihak swasta telah membangun beberapa rumah sakit. Untuk wilayah yang jauh dari perkotaan, pemerintah tidak tinggal diam dalam hal ini, buktinya melalui dana $A P B D$, pemerintah telah membangunbeberapa puskesmas pembantu (Pustu), dan salah satunya puskesmas pembantu (pustu) puskesmas pembantu (pustu) Rante Malolinnyang ada di Kelurahan Peta Kecamatan Sendana Kota Palopo.

Tak heran bila sebagian masyarakat mengadakan pegobatan di puskesmas lain, atau pun kerumah sakit yang membutuhkan waktu dan biaya tambahan. Berdasarkan penelitian, masyarakat sekitar menyatakan bahwa kepuasan dalam pelayanan kesehatan belum mereka rasakan.

Semoga dengan hasil penelitian !! petugas puskesmas pembantu (Pustu) Rante Malolin dapat meningkatkan kinerja nya sebagai pelayanan kesehatan masyarakat, agar tujuan visi pemerintah indonesia yakni sehat 2010 dapat tercapai, dan melalui pembagunan kesehatan.

Dengan tujuan meningkatkan kualitas sumber daya manusia yang dilakukan secara berkelanjutan.
\end{abstract}

Kata kunci : pelayanan persepsi,pekerjaan kesehatan, kualitas. 


\section{Pendahuluan}

\section{Latar belakang}

Kesehatan merupakan hak azasi sehingga setiap masyarakat berhak memperoleh pelayaana kesehatan secara adil, merata dan bermutu yang menjangkau seluruh masyarakat Indonesia. Indonesia sehat 2010 merupakan visi pembagunan nasional yang ingin dicapai melalui pembangunan kesehatan dengan tujuan meningkatkan kualitas sumber daya manusia yang dilakukan secara berkelanjutan. Dalam upaya mencapai visi tersebut ditetapkan program-program unggulan, salah satunya adalah program keselamatan dan kesehatan kerja (K3) (Departemen Kesehatan RI, 2003:1) untuk mewujudkan keadaan sehat banyak hal yang perlu dilakukan salah satu diantaranya yang dinilai mempunyai peranan yang cukup penting adalah penyelenggara pelayanan kesehatan. (A.A. Gde Muninjaya. 1999:14).

Salah satu sarana pelayanan kesehatan yang mempunyai pesan sangat penting dalam memberikan pelayanan kesehatan kepada masyarakat adalah puskesmas pembantu (Pustu) mengemban tugas untuk memberikan pelayanan kesehatan kepada seluruh masyarakat, karena pembangunan dan penyelenggaraan kesehatan di puskesmas pembantu (pustu) perlu diarahkan pada tujuan nasional di bidang kesehatan.

Puskesmas pembantu (pustu) sebagai salah satu fasilitas pelayanan kesehatan memiliki peran yang sangat strategis dalam upaya mempercepat peningkatan derajat kesehatan masyarakat Indonesia. Pola pelayanan kesehatan yang diharapkan adalah pelayanan yang berkualitas, sehingga mampu mereduksi angka kesakitan dan kematian serta menciptakan masyarakat sehat sejahtera. Masalah penelitian ini adalah bagaimana persepsi masyarakat terhadap pelayanan kesehatan pada Pustu Rante Malolin Kelurahan Peta Kecamatan Sendana Palopo. Tujuan penelitian ini adalah Untuk mengetahui persepsi masyarakat trhadap pelayanan kesehatan Pada Pustu Rante Malolin Kelurahan Peta Kecamatan Sendana Kota Palopo.

\section{Metode Penelitian}

Tempat dan waktu penelitian

Penelitian ini dilaksanakan di puskesmas pembantu (Pustu) Rante Malolin Kelurahan Peta Kecamatan Sendana Kota Palopo yang merupakan milik pemerintah. Adapun waktu pelaksanaan penelitian direncanakan pada Bulan Februari 2012 sampai dengan Bulan Maret 2012.

Jenis dan sumber data

a. Data primer

Data primer adalah data yang diperoleh dari responden melalui wawancara langsung berpedoman pada kuesioner yang telah disiapkan 


\section{b. Data sekunder}

Data sekunder diperoleh dari beberapa buku sebagai referensi, surat kabar, dan majalah yang ada hubungannya dengan pokok masalah serta catatan rekam medis manajemen Pustu.

\section{Populasi dan Sampel}

Populasi dalam penelitian ini adalah masyarakat sekitar Pustu dengan kriteria 135 jiwa responden dan total populasi masyarakat dengan kriteria: apabila populasi besar, lebih dari 100 maka peneliti dapat mengambil seluruhnya, karena bila populasinya berkisar 130 jiwa maka sampel yang penulis teliti adalah sebanyak 50\% dari populasi yakni \pm 50 orang. Maka peneliti dapat menggunakan sampel yang diambil dari populasi itu.apayang dipelajari dapat menggunakan sampel itu, kesimpulannya akan dapat diberlakukan untuk populasi. Untuk itu sampel yang diambil dari populasi harus betul-betul representative (mewakili).

Metode pengumpulan data

Metode pengumpulan data yang digunakan adalah: (a) Penelitian lapangan; Adalah penelitian yang dilakukan secara langsung pada obyeknya, untuk mendapatkan data yang dibutuhkan secara langsung. Cara-cara yang dilakukan adalah : (1) Observasi, yaitu pengamatan dan pencatatan secara sistematis terhadap gejala/fenomena yang diselidiki, (2) Interview, yaitu mengadakan wawancara langsung pada pihak-pihak yang dapat memberikan keterangan yang diperlukan, (3) Kuestioner, yaitu memberikan daftar pernyataan pada responden untuk memperoleh data yang diperlukan, responden tinggal memilih beberapa alternative jawaban, (b) Penelitian Kepustakaan (Library Research); Adalah penelitian yang bersumberkan pada perpustakaan, seperti surat kabar, majalah dan brosur-brosur yang ada hubungannya dengan pokok masalah.

Metode analisis data

Metode analisis data dalam penelitian ini menggunakan regresi linear berganda yaitu $\mathrm{Y}=\mathrm{b} 0+\mathrm{b} 1 \mathrm{X} 1+\mathrm{b} 2 \mathrm{X} 2+\mathrm{b} 3 \mathrm{X} 3$.

$$
\begin{array}{ll}
\text { Di mana } & = \\
\mathrm{Y} & =\text { kepuasan } \\
\mathrm{X}_{1} & =\text { keterampilan (professionalism) } \\
\mathrm{X}_{2} & =\text { kehandalan (Reliability) } \\
\mathrm{X}_{3} & =\text { sikap atau Tingkah Laku (Attitudes) } \\
\mathrm{b}_{0} & =\text { konstanta } \\
\mathrm{b}_{1}-\mathrm{b}_{3} & =\text { parameter yang di ukur }
\end{array}
$$




\section{Hasil Penelitian Dan Pembahasan}

\section{Hasil penelitian}

Gambaran umum puskesmas pembantu (pustu) Rante Malolin

Puskesmas pembantu (Pustu) Rante Malolin adalah Puskesmas pembantu milik pemerintah Kota Palopo. Dimana lokasinya berada di RT1 RW2 Rante Malolin Kelurahan Peta Kecamatan Sendana Kota Palopo. Keadaan Puskesmas Pembantu (Pustu) Rante Malolin sangat sejuk oleh karena letaknya berada pada daerah pengunugan yang disekitarnya terdapat beberapa pohon termasuk buah-buahan yakni pohon rambutan, pohon durian dan tanaman nilam. Akses menuju puskesmas pembantu (pustu) Rante Malolin terdapat dua akses yang pertama sebelah utara tepatnya di kilometer lima Latuppa kemudian menyebrang sungai. Untuk menyebrangi sungai bisa saja dilalui dengan motor dengan catatan air tidak meluap atau keadaan air di bawah kaki, tetapi bila keadaan air sungai meluap, maka harus dilalui dengan jalan kaki. Akses kedua yaitu melalui darat sebelah timur tepatnyaharus melewati dua gunung yang keadaannya sangat rawan oleh karena gunung yang pertama merupakan daerah longsor, sedangkan kondisi jalan penuh bebatuan.

\section{Pembahasan}

Distribusi frekuensi karakteristik Responden Berdasarkan Umur Dapat Dilihat Pada Tabel Empat Satu Berikut ini

Tabel 4.1

Klasifikasi Responden Berdasarkan Umur

\begin{tabular}{|l|l|l|l|}
\hline No & Umur & $\begin{array}{l}\text { Jumlah } \\
\text { Responden }\end{array}$ & Persentase (\%) \\
\hline 1 & $<25$ Tahun & 14 & 0,28 \\
\hline 2 & $25-34$ Tahun & 9 & 0,18 \\
\hline 3 & $35-44$ Tahun & 12 & 0,24 \\
\hline 4 & $45-54$ Tahun & 6 & 0,12 \\
\hline 5 & $>55$ Tahun & 9 & 0,18 \\
\hline & Total & 50 & 100,00 \\
\hline
\end{tabular}

Hasil penelitian menunjukkan, berdasarkan umur $<25$ tahun, terdapat 14 responden, atau sekitar (0,28\%). Berdasarkan umur antara 25 - 34 tahun terdapat 9 responden, atau sekitar $(0,18 \%)$, berdasarkan umur antara 35 - 44 tahun terdapat 12 responden, atau sekitar $(0,24 \%)$, berdasarkan umur antara $45-54$ tahun terdapat 6 responden, atau sekitar $(0,12 \%)$, berdasarkan umur 55 tahun keatas terdapat 9 responden, atau sekitar $(0,18 \%)$. 


\section{Penutup}

Kesimpulan penelitian ini adalah: (a) Berdasarkan analisis persamaan regresi baerganda; Persamaan regresi yang dihasilkan $\mathrm{Y}=0,665-0,91\left(\mathrm{X}_{1}\right)+0,242\left(\mathrm{X}_{2}\right)+$ 0,492 $\left(\mathrm{X}_{3}\right)$. Jika variabel keterampilan, kehandalan, sikap atau tingkah laku sama dengan nol, maka persepsi pasien meningkatnya pasien sebesar 0,665. Bila kualitas pelyanan berubah menjadi satu, maka variabel kehandalan yaitu sebesar $0,242 \%$, (b) Berdasarkan uji koefisien determinasi $\left(\mathrm{R}_{2}\right)$; Nilai $\mathrm{R}$ adalah 64,7 persen.Hal ini menunjukkan bahwa 64,7 persen kepuasan pasien atau masyarakat dapat di jelaskan oleh variabel kehandalan dan sikap atau tingkah laku. Adapun saran dari penelitian ini adalah: (a) Karena variabel sikap atau tingkah laku sangat berpengaruh terhadap kepuasan pasien atau masyarakat.Variabel kehandalan tidak terbukti terhadap kepuasan pasien atau masyarakat maka dengan ini di sarankan kepada perawat Pustu Rante Malolin agar dapat meningkat kan ketrampilan, (b) Kehandalan dan sikap atau tingkah laku seperti variabel emphaty yaitu dengan memberikan perhatian yang lebih kepada masyarakat sekitar,sehingga dengan demikain kepuasan pada pelayanan kesehatan pustu Rante Malolin Kelurahan pada Peta Kecamatan Sendana Kota Palopo.

\section{Daftar Pustaka}

A.A Gde Muninjay (1999: 14) kesehatan Masyarakat_volume 2 / No 2 / januari juni

Adisasmito wiko (2009:3) sistem manajemen Lingkungan Rumah Sakit Edisi 1-2, Rajawali pers: Jakarta

Aditama Yoga (2003:157)Majemen admidstrasi Rumah Sakit Edisi kedua penerbit Universitas Indonesia-jaakarta

------(2003:163) manajen administrasi Rumah sakit Edisi kedua Penerbit Universitas Indonesia jakarta 